\title{
Analisa Pemetaan Kawasan Rawan Banjir di Kabupaten Kampar
}

\author{
Nurdin', Fakhri² \\ ${ }^{1,2}$ Fakultas Teknik Universitas Riu \\ Nurdin.gis@gmail.com
}

\begin{abstract}
Kampar District is traversed by two large rivers and several small rivers, including Kampar River which is $\pm 413.5 \mathrm{~km}$ long with an average depth of $7.7 \mathrm{~m}$, and an average width of $143 \mathrm{~m}$. Referring to Central Statistics Agency Kampar Regency (2015), Kampar residents numbered 703,005 people with a growth of $2.57 \%$ that exceeded the national population growth in 2010 of 1.49\%. The Kampar Kanan River has a much larger flood impact than Kampar Kiri River because the majority of the population lives along the banks of the Kampar Kanan River. Areas that are always targeted need to be mapped in the form of flood vulnerability maps within Kampar regency. To map areas susceptible to flooding in Kampar District can be done using remote sensing data based on Geographic Information System (GIS). Analysis of the overlay map results as an indicator of flooding in 4 flood vulnerability classes in Kampar regency. Overlaid maps consist of Rainfall Map, Slope Map, Land Use Map and Geological Map, which resulted in the widest area in Kampar District in the prone category of 459,977.89 ha or 42.86\% of the district area. The second sequence is in the non-vulnerable category 236,082.39 ha or 22.00\%. While the order of the 3rd area is in very vulnerable category that is 219.279 .54 ha or $20.43 \%$, and the smallest area is in the safe category of 157,835.01 ha or 14.71\% of Kampar Regency area.
\end{abstract}

Key words: Geographic Information System, Watersheds, Data raster/vector, Overlay, flood-prone areas.

Kabupaten Kampar memiliki batas-batas : Utara - Kota Pekanbaru, Kabupaten Siak; Selatan Kabupaten Kuantan Singingi; Barat Kabupaten Rokan Hulu, Provinsi Sumatera Barat; Timur - Kabupaten Pelalawan dan Siak. Kabupaten Kampar terdiri dari 21 Kecamatan didiami oleh 793.005 jiwa dengan kepadatan 71 jiwa $/ \mathrm{km}^{2}$ atau rata-rata jumlah penduduk 4 jiwa per rumah tangga. Kepadatan penduduk di 21 Kecamatan cukup beragam dengan kepadatan tertinggi terletak di Kecamatan Kampar sebesar 371 jiwa $/ \mathrm{km}^{2}$ dan yang terendah di Kecamatan Kampar Kiri Hulu 10 jiwa $/ \mathrm{km}^{2}$ (BPS. Kabupaten Kampar, 2016).

Sebagian besar Kabupaten Kampar berada dalam DAS Kampar dan sebagian kecil termasuk ke dalam DAS Siak. Sungai-sungai besar yang terdapat di Kabupaten Kampar ini sebagian masih berfungsi sebagai sarana perhubungan, sumber air bersih, budi daya ikan, maupun sebagai sumber energi listrik (PLTA Koto Panjang) (Profil Kabupaten Kampar, 2017) Ada beberapa kejadian banjir dalam tiga tahun terakhir seperti kutipan dalam Media
Center (2014) Begitu juga dengan artikel yang ditulis oleh Rahmat (2016), hingga kamis (11/2/2016) bencana banjir masih menggenangi beberapa kecamatan dengan 26.614 kepala keluarga yang terdampak. Menurut Haryani (2008) secara gemorfologis daerah rawan banjir terdapat pada bentuk lahan marine, aluvial, dan uvio marine (uvio marine merupakan gabungan bentuk lahan marine dan bentuk lahan alluvial). Penelitian oleh Sukiyah (2004) mendapatkan kawasan rentan banjir yang ditinjau dari beberapa aspek penyebab banjir.

Untuk melakukan pemetaan wilayah yang rentan terkena banjir di wilayah Kabupaten Kampar dapat dilakukan dengan bantuan data penginderaan jauh yang berbasiskan Sistem Informasi Geografis (SIG). Abidin (2002) mengatakan, untuk pengukuran dan pemetaan dipermukaan bumi dapat dilakukan dengan pengukuran GPS, Penginderaan Jauh (Remote Sensing) dan pemanfaatan teknologi SIG. Menurut Sukojo (2005), perkembangan software SIG saat ini, telah mampu menggabungkan data image/raster dan vektor 
ditambah database untuk eksplorasi informasi berbasis koordinat bumi.

SIG dapat dimanfaatkan untuk membangun sistem untuk pemetaan potensi bencana seperti misalnya banjir, sehingga dapat mengetahui dimana daerah-daerah yang rawan bencana banjir di daerah tersebut. Menurut Prahasta (2009) SIG adalah salah satu sistem yang komplek dan pada umumnya juga (selain yang stand-alone) terintegrasi dengan lingkungan sistem komputer lainnya di tingkat fungsional dan jaringan (network). Begitu juga dengan Ekadinata et al. (2008) SIG juga merupakan sebuah sistem atau teknologi berbasis komputer yang dibangun dengan tujuan untuk mengumpulkan, menyimpan, mengolah dan menganalisa. Sedangkan Elly (2009) SIG menarik minat sebagian besar orang untuk mengimplentasikan teknologi ini dalam berbagai bidang. Charter (2004) mengatakan, SIG lebih mengarah pada teknologi informasi yang digunakan untuk pengumpulan, penyimpanan, analisa dan penampilan data-data spasial (geographic) dan data-data non spasial, dengan komponen yang terdiri dari komputer (software dan hardware). Nurdin (2015) telah membuktikan penggunaan peranfkat SIG dapat melaksanaan pemetaan kawasan rentan banjir di Kota Pekanbaru.

Bagaimanakah cara memetakan wilayah yang rentan terkena banjir di Kabupaten Kampar yang tercakup dalam DAS Kampar dan sebagian kecil di DAS Siak yang berada selalu menjadi langganan banjir terutama pada musim hujan dengan bantuan perangkat pengolah data GIS berdasarkan hasil identifikasi data penginderaan jauh, jenis tanah, kelerengan dengan metode overly. Untuk itu diperlukan identifikasi daerah yang rentan terkena banjir di Kabupaten Kampar sehingga, akan menghasilkan peta kerawanan banjir di Kabupaten Kampar terutama wilayah yang ada di dalam DAS Kampar. Urgensi dari penilitian ini adalah untuk mendapat peta kerawanan banjir yang dapat dimanfaatkan dalam mengambil kebijakan terutama dalam penanggulangan dan mencari solusi bencana banjir di Kabupaten Kampar dan daerah berpotensi banjir di dalam Kota Pekanbaru.

\section{BAHAN DAN METODE}

Lokasi penelitian adalah Kabupaten Kampar yang sebagian besar berada dalam DAS Kampar, DAS Siak dan sebagian kecil dalam DAS Rokan.

Perangkat pengolah data pada penelitian ini menggunakan perangkat keras terdiri Laptop, sedangkan perangkat lunak terdiri perangkat SIG yang bekerja pada sisten operasi Windows.

Pengumpulan data dilakukan untuk identifikasi permasalahan banjir yang terjadi di Kabupaten Kampar berupa sejarah kejadian banjir yang ada di semua wilayah, penggunaan lahan, kondisi tofografi dan lain-lain berupa data sekunder didapatkan dari instansi terkait yang diperlukan untuk mendukung analisa daerah rawan banjir di Kabupaten Kampar meliputi: Peta digital Provinsi Riau dari BPS tahun 2010, Peta kelas kemiringan lahan Provinsi Riau dari BPDAS Indragiri Rokan, Data Curah Hujan hasil pengukuran curah hujan di 4 stasiun hujan dari BWS Sumatera III, Peta penggunaan lahan Provinsi Riau tahun 2011 dari BPDAS Indragiri Rokan sebagai acuan pembuatan Peta Penggunaan lahan tahun 2014, Citra Satelit Landsat tahun 2014 untuk keperluan peta penggunaan lahan di Kabupaten Kampar tahun 2014, dan Peta Gelogi Sumatera yang diperoleh dari BPDAS Indragiri Rokan. Pengumpulan data primer melalui survey langsung ke lapangan untuk : Mendapatkan informasi penutup lahan dan lokasi kejadian banjir, dan kunjungan ke masyarakat serta melakukan wawancara.

Analisa nilai kerawanan banjir di Kabupaten Kampar dilakukan adalah terhadap 4 parameter yang diambil sebagai indikator kerawanan banjir yaitu : Penggunaan lahan/penutup lahan, curah bujan, kemiringan lereng, dan formasi jenis geologi batuan. Nilai kerawanan banjir ditentukan dari total penjumlahan skor seluruh parameter yang dipakai dalam analisis (yang berpengaruh terhadap banjir). Daerah yang sangat rawan terhadap banjir mempunyai total skor yang tinggi, sebaliknya daerah yang tidak rawan terhadap banjir akan mempunyai total skor yang rendah dapat dicari menggunakan persamaan sebagai berikut: 
$K=\sum_{i=1}^{n}\left(W_{1} x X_{i}\right)$

dengan :

$K=$ Nilai kerawanan

$W_{i}=$ Bobot untuk parameter ke-i

$X_{i}=$ Skor kelas pada parameter ke-i

Menurut Kingma (1991) dalam Handani, et al. (2014) untuk menentukan tingkat kerawanan dapat ditentukan dengan persamaan sebagai berikut:

$I=\frac{R}{n}$

dengan :

$\mathrm{I}=$ Lebar interval

$\mathrm{R}=$ Selisih skor maksimum dan skor minimum

$\mathrm{n}=$ Jumlah kelas kerawanan banjir

\section{HASIL}

\section{Curah Hujan}

Berdasarkan 4 stasiun pengukur hujan di Kabupaten Kampar, didapat data curah hujan tahunan rata-rata dari 1 Januari 2010 - 31 Desember 2014. Dengan menggunakan metode Poligon Thiessen didapat curah hujan terendah 2.271,84 mm pada stasiun curah hujan Pasar Kampar, sedangkan curah hujan tahunan tertinggi adalah 2.836,65 $\mathrm{mm}$ terdapat pada stasiun hujan Petapahan. Pembagian kelas curah hujan oleh Asdak (2010) terdapat 5 kelas, curah hujan. Kelas curah hujan dan pemberian skor disajikan dalam Tabel 1. Nilai skor diberikan berdasarkan pengaruh curah hujan terhadap kemungkinan terjadinya banjir, skor tertinggi 100 diberikan pada curah hujan diatas 2.500 $\mathrm{mm}$, sedangkan skor terendah 20 diberikan pada curah hujan terendah yakni dibawah 1.000 $\mathrm{mm}$.

Tabel 1. Kelas dan nilai skor curah hujan tahunan terhadap rawan banjir

\begin{tabular}{ccc}
\hline No & \multicolumn{1}{c}{$\begin{array}{c}\text { Curah Hujan } \\
(\mathrm{mm})\end{array}$} & $\begin{array}{c}\text { Nilai } \\
\text { skor }\end{array}$ \\
\hline 1 & $<1.000$ (sangat rendah) & 20 \\
2 & $1001-1500$ (rendah) & 40 \\
3 & $1501-2000$ (sedang) & 60 \\
4 & $2001-2500$ (tinggi) & 80 \\
5 & $>2500$ (sangat tinggi) & 100 \\
\hline
\end{tabular}

\section{Kemiringan Lahan}

Peta kelas lereng tanah di Kabupaten Kampar dari berasal dari Peta Kelas lereng DAS dalam Provinsi Riau dari BPDAS Indragiri Rokan hanya terdapat 4 kelas lereng sejalan Asdak (2010 $)^{[14]}$ yang membagi kelas kemiringan tanah dalam 4 kelas.

Tabel 2. Kelas kemiringan berserta nilai skor rawan banjir

\begin{tabular}{lr}
\hline \multicolumn{1}{c}{ Ko Kelas Lereng } & \multicolumn{1}{c}{ Nilai Skor } \\
\hline $1<8 \%$ (datar) & 100,00 \\
$28 \%-15 \%$ (Landai) & 80,00 \\
$316 \%-25 \%$ (Agak curam) & 60,00 \\
$4>40 \%$ (Sangat curam) & 20,00 \\
5 Tubuh air & 100,00 \\
\hline
\end{tabular}

Kemiringan tertinggi diatas $40 \%$ mempnyai luasan $283.708,00$ ha $(26,50 \%)$, sedangkan kerimiringan terendah dibawah $8 \%$ dengan luasan $434.653,00$ ha $(40,60 \%)$. Kemiringan tanah terendah dibawah $8 \%$ merupakan indikator kawasan paling rawan terhadap bencana banjir dikarenkan sifat air mencari tempat yang lehih rendah. Pemberian skor dengan modifikasi, terhadap 4 kelas lereng dengan nilai skor terendah 20 pada kelas lereng $>40 \%$, sedangkan skor tertinggi 100 diberikan pada kelas lereng terendah $<8 \%$, seperti disajikan pada Tabel 2.

\section{Penutupan Lahan}

Penggunaan lahan tahun 2014 yang diinterpretasi berdasarkan pola penggunaan lahan tahun 2011 tersebut berjumlah 16 kelas yang terdiri dari; Tubuh air, Hutan lahan kering primer, Hutan lahan kering sekunder, Hutan rawa sekunder, Hutan tanaman, Kebun campuran, Perkebunan, Pemukiman, Pertambangan/Tambang, Pertanian lahan kering, Pertanian lahan kering bercampur semak, Sawah, Semak/Belukar, Semak belukar rawa, Tambak, dan Tanah terbuka. Penutup lahan terluas terdapat pada perkebunan $311.511,25$ ha atau $29,10 \%$, sedangkan luasan terkecil terdapat pada tubuh air 74,63 ha $(0,1 \%)$ dari luas Kabupaten Kampar. 
Tabel 3. Kelas dan nilai skor kerawanan banjir untuk penggunaan lahan

\begin{tabular}{cc}
\hline No $\quad$ Jenis penggunaan lahan & Skor \\
\hline 1 Tubuh air, Sawah, Tambak, Semak/Belukar & 100 \\
rawa, Hutan rawa sekunder, Tanah terbuka & \\
2 Pertanian lahan kering, Pertanian lahan & 80 \\
& kering bercampur semak, kebun campuran, \\
& \\
Semak/Belukar, & \\
3 Pemukiman, Pertambangan/Tambang & 60 \\
& \\
2 Perkebunan, Hutan tanaman & 40 \\
5 Hutan lahan kering primer, Hutan lahan & 20 \\
& kering sekunder \\
\hline
\end{tabular}

Untuk melihat pengaruh dari jenis penggunaan dari penutup lahan terhadap kerawanan banjir yang terjadi terhadap wilayah Kabupeten Kampar, jenis penggunaan lahan ini dikelompokkan dengan nilai skor dari 20 sampai dengan 100. Hutan lahan kering primer dan Hutan lahan kering sekunder adalah jenis penggunaan lahan yang dianggap paling kecil memberikan perangruh terhadap terjadinya banjir hingga diberikan skor paling kecil yakni 20. Sedangkan Tubuh air, Hutan rawa sekunder, Semak /belukar rawa,Tambak, dan Tanah terbuka adalah jenis penggunaan Sedangkan Tubuh air, Hutan rawa sekunder, Semak /belukar rawa,Tambak, dan Tanah terbuka adalah jenis penggunaan lahan yang diperkirakan dapat memberikan nilai skor yang paling tinggi yakni nilai 100 seperti Tabel 3.

Tabel 3. nilai skor rawan Penggunahan lahan terbuka

\begin{tabular}{|c|c|}
\hline Jenis penggunaan lahan & Skor \\
\hline $\begin{array}{l}1 \text { Tubuh air, Sawah, Tambak, Semak/Belukar } \\
\text { rawa, Hutan rawa sekunder, Tanah terbuka }\end{array}$ & 100 \\
\hline $\begin{array}{l}2 \text { Pertanian lahan kering, Pertanian lahan } \\
\text { kering bercampur semak, kebun campuran, } \\
\text { Semak/Belukar, }\end{array}$ & 80 \\
\hline 3 Pemukiman, Pertambangan/Tambang & 60 \\
\hline 4 Perkebunan, Hutan tanaman & 40 \\
\hline $\begin{array}{l}5 \text { Hutan lahan kering primer, Hutan lahan } \\
\text { kering sekunder }\end{array}$ & 20 \\
\hline
\end{tabular}

\section{Geologi}

Dari formasi jenis batuannya di Kabupaten Kampar ini terdapat 16 formasi jenis batuan yang tersusun oleh perbukitan curam hingga dataran rendah. Wilayah yang paling luas adalah jenis Aluvium tua seluas 278.279,40 ha atau 25,99\% dari luas Kabupaten Kampar yang tersebar di Kecamatan Tapung, Tapung Hilir, Tapung Hulu, Kampar Kiri Hilir, Siak Hulu, Perhentian Raja, Kampar Kiri, Rumbio Jaya, Kampar Timur, Tambang, Kampar Utara,
Kampar Kiri Tengah, dan Bangkinag Seberang. Jenis formasi geologi terkecil terdapat pada jenis Formasi Gunungapi Kota Alam seluas 97,20 ha atau $0,1 \%$ dari luas Kabupaten Kampar yang tersebar di Kecamatan kampar Kiri Hulu.

Indikator pengaruh geologi tehadap banjir dicirikan dengan pemberian warna tua hingga ke warna muda, dengan asumsi warna tua adalah formasi jenis batuan yang sangat keras dan sangat sulit untuk ditembus air, sedangkan warna muda adalah formasi jenis batuan yang mudah ditembus oleh air, sejalan dengan Raharjo. et al. (2011) dimana, wilyah yang sering mendapatkan banjir sering terjadi pada bentuk lahan fluviatil, yaitu pada dataran aluvium dan dataran fluviatil. Dari 16 formasi jenis batuan yang ada di Kabupaten Kampar, skor tertinggi dengan nilai 100 diberikan pada formasi jenis batuan Aluvium, Aluvium tua, Aluvium muda, Anggota Tanjung Pauh, Batuan Gunungapi Rhyo-andesite, sedangkan skor terendah 20 diberikan pada Granit ulak, Granit dan Granit Pulau Gading seperti disajikan dalam Tabel 4.

Tabel 4. Jenis formasi geologi dan nilai skor rawan banjir.

\begin{tabular}{llc}
\hline No & \multicolumn{1}{c}{ JENIS FORMASI } & Skor \\
\hline 1 Aluvium, Aluvium Muda, Aluvium & 100 \\
& muda, Formasi Tanjung Pauh, Batuan \\
& Gunungapi Rhyo-andesite, Formasi & \\
& Bahorok \\
& 2 Formasi Brani, Formasi Gunugapi & \\
& Koto Alam, Formasi Kuantan, \\
& Formasi Minas, Formasi Palembang, \\
& Formasi Ombilin, \\
& 3 Formasi Pematang, Formasi Petani, \\
& Formasi Sihapes \\
& 4 Formasi Telisa, Formasi Tahur \\
& 5 Granit, Granit Ulak, Granit Pulau \\
& Gading & 60 \\
\end{tabular}

\section{PEMBAHASAN}

\section{Analisa Kerawanan Banjir}

Dalam menganalisa kerawanan terhadap terjadinya banjir di Kabupaten Kampar adalah dengan tumpang susun (Overlay) antar peta curah hujan, peta kelas lereng, peta penggunaan lahan dan peta geologi dalam proses geoprocesing intersect yang tersedia dalam 
perangkat SIG. Peta hasil overlay diberikan skor dan pembobotan seperti yang dilakukan oleh Darmawan, et al. (2017) terhadap masingmasing jenis peta yang ada didalamnya, dimana pada peta curah hujan diberi bobot 0,3 peta kelas lereng 0,2 dan peta penggunaan lahan diberi bobot 0,3 dan peta geologi 0,2 . Pertimbangan pemberian bobot ini berdasarkan besarnya pengaruh masing-masing parameter terhadap kerawanan banjir dan juga berdasarkan jurnal-jurnal terdahulu yang relevan terhadap kajian ini seperti disajikan dalam Tabel 5.

Tabel 5. Pembobotan parameter penyebab banjir yang ditinjau

\begin{tabular}{|c|c|c|}
\hline No & Parameter yang ditinjau & Bobot (\%) \\
\hline & h Hujan & 0,3 \\
\hline & s Lereng & 0,2 \\
\hline & gunaan Lahan & 0,3 \\
\hline & & 0,2 \\
\hline
\end{tabular}

Zona tingkat kerawanan banjir di Kabupaten Kampar didapat dari hasil perkalian antara skor curah hujan dengan bobot curah hujan + perkalian skor lereng dengan bobot lereng + perkalian skor penggunaan lahan dengan bobot penggunaan lahan dan + perkalian skor jenis formasi geologi dengan bobot jenis formasi geologi. Tingkat/kelas kerawanan banjir yang didapat sejalan pula dengan Kingma (1991) dalam Hamdani, et al. (2014), didapat dengan membagi sama banyak nilai-nilai kerawanan dengan jumlah interval kekas. Hasil perkalian skor dan bobot ini diberikan nilai dalam interval tingkat kerawanan banjir. Nilai sangat rawan dengan interval nilai 86 - 100, rawan dengan interval nilai 72 - 86, tidak rawan nilai interval 58 - 72 dan kategori aman dengan nilai interval 44 - 58 seperti ditunjukkan dalam Tabel 6.

Tabel 6. Tingkat kerawanan banjir di Kabupaten Kampar

\begin{tabular}{llc}
\hline \multirow{2}{*}{ No $\quad$ Tingkat Kerawanan Banjir } & Interval \\
\cline { 2 - 2 } & Nilai kerawanan \\
\hline 1 Aman & $44-58$ \\
Tidak Rawan & $58-72$ \\
3 Rawan & $72-86$ \\
4 Sangat Rawan & $86-100$ \\
\hline
\end{tabular}

Gambar seacara spasial yang disajikan pada Gambar 1, dan luasan masingmasing kategori tingkat kerawan banjir di Kabupaten Kampar secara numeris disajikan pada Tabel 7.

Tabel 7. Luas dan rasio tingkat kerawanan banjir di Kabupaten Kampar

\begin{tabular}{lrr}
\hline No ingkat Kerawan` & \multicolumn{2}{c}{ Luas } \\
\hline 1 Aman & (\%) \\
2 Tidak Rawan & $157.835,01$ & 14,71 \\
3 Rawan & $236.082,39$ & 22,00 \\
4 Sangat Rawan & $459.977,89$ & 42,86 \\
\hline Jumlah & $219.279,54$ & 20,43 \\
\hline
\end{tabular}

Kawasan dengan kategori sangat rawan terhadap kerawanan banjir adalah seluas 219.279,54 ha atau 20,43\% dari luas Kabuapten Kampar. Pada kawasan ini sangat rawan sekali jika diperuntukkan untuk lokasi pemukiman, jika kawasan pemukiman tidak dapat dihindari dari kawasan ini sebaiknya model pemukiman dapat disesuaikan dengan kondisi yang ada misalnya mendirikan bangunan rumah panggung dan pembangunan drainase yang layak untuk mengalirkan air dari tempat yang lebih tinggi ke sungai. Tingkat kerawanan terhadap bencana banjir yang merupakan kawasan terluas dari 4 tingkat kerawanan yang ada adalah kategori rawan yakni, 459.977,89 ha atau 42,86\% dari luas Kabupaten Kampar. Pada kawasan ini diperlukan saluran drainase pada daerah tertentu untuk penyaluran air ke sungai dalam mengantisipasi kerawanan banjir. Sedangkan kawasan dengan kategori tidak rawan seluas 236.082,39 ha atau $22,00 \%$ serta kawasan pada kategori aman (luasan terkecil dari 4 kelas kerawanan) yakni, 157.835,01 ha atau $14,71 \%$ dari luas Kabupaten Kampar. Pada kawasan kategori tidak rawan dan aman hanya diperlukan pengelolaan yang baik terhadap fungsi kawasan agar tidak terjadi perubahan fungsi kawasan yang mengakibatkan kerusakan. 


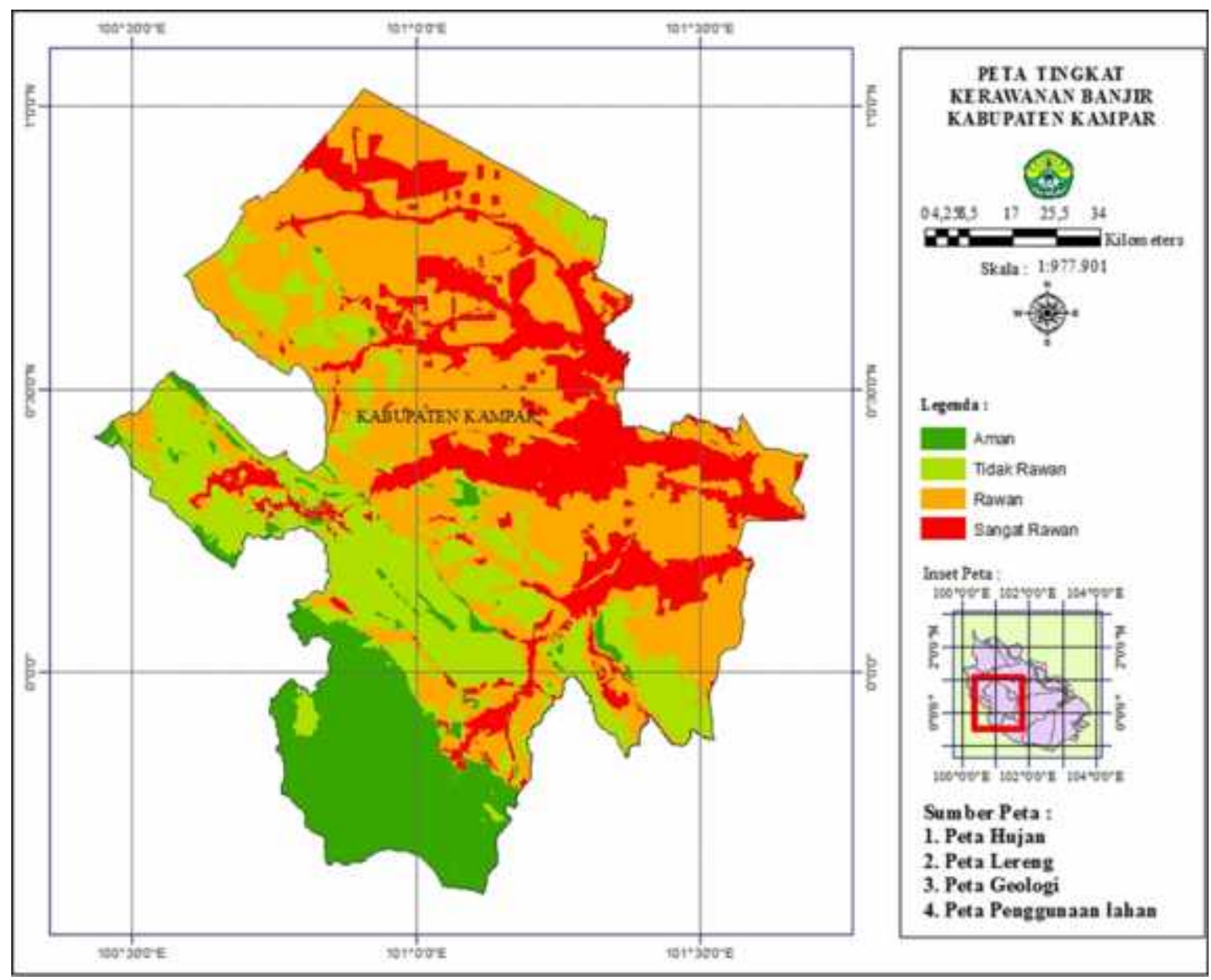

Gambar 1. Peta tingkat rawan banjir di Kabupaten Kampar

\section{SIMPULAN}

Dari hasil analisa yang dilakukan terhadap hasil overlay antar peta yang dijadikan parameter penyebab banjir di Kabupten Kampar dapat disimpulkan :

1. Wilayah yang terluas berada dalam kategori rawan terhadap kerawanan banjir yakni $459.977,89$ ha atau 42,86\% dari luas Kabuapten Kampar.

2. Luasan urutan ke 2 berada pada kategori tidak rawan seluas $236.082,39$ ha atau $22,00 \%$ dari luas Kabuapten Kampar.

3. Sedangkan urutan luas terbesar ke 3 terdapat pada kategori sangat rawan seluas 219.279,54 ha atau 20,43\% dari luas Kabuapten Kampar.

4. Sedangkan luasan terkecil terdapat pada kategori aman seluas 157.835,01 ha atau $14,71 \%$ dari luas Kabuapten Kampar.

\section{UCAPAN TERIMA KASIH}

Semua pihak yang telah banyak membantu baik material maupun non material demi mendukung penelitian ini

\section{DAFTAR PUSTAKA}

Abidin, H.Z. (2002). Survei Dengan Global Position System (GPS). PT Pradnya Pramita. Jakarta.

Asdak, C. 2010. Hidrologi dan pengelolaan Dearah Aliran Sungai. Gajah Mada University Press. Yogyakarta.

BPS Kabupaten Kampar. 2016. Kampar dalam angka. Badan Pusat Statistik Kabupaten Kampar. Bangkinang.

Charter, D (2004) Mapinfo professional, Informatika Bandung, Bandung.

Darmawan, K., Hani'ah, dan A. Suprayogi. 2017. Analisis tingkat kerawanan banjir di Kabuapten Sampang menggunakan metode 
overlay dengan scoring berbasis system informasi geografis. Jurnal Geodesi.

Ekadinata, A. Sonya, D. Danan, P. H. Dudy dan K. N. Feri. 2008. Sistem inormasi geografis : Untuk pengelolaan bentang lahan berbasis sumber daya alam. World Agrofprestry Centtre. Bogor.

Elly, M. J. 2009. Sistem informasi geografi menggunakan aplikasi ArcView 3.2 dan Ermapper 6.4. Graha Ilmu, Yogyakarta.

Hamdani, H., S. Permana, A. Susetyaningsih. 2014. Analisis daerah rawan banjir menggunakan aplikasi system informasi geografis (Stusi kasus Pulau Bangka). Jurnal STT-Garut Allright Reserved. 12 (1) : $1-13$.

Haryani, N. S. 2008. Model simulasi banjir menggunakan data penginderaan jauh (Studi kasus Kabupaten Sampang menggunakan metode gredded surface sub-surface hidrologic analisys). Jurnal Penginderaan Jauh. 9 (2) : 90- 101.

Media Center. 2014. Banjir Kmapar ditetapkan sebagai daerah tangkap darurat bajir.

http://www.mediacenter.or.id/reports/vi ew/876\#.WI2rIVJWVqM 29 Januari 2017, Pukul 16.57 WIB.

Nurdin. 2015. Pemetaan kawasan rentan banjir dalam Kota Pekanbaru menggunakan sistem informasi geografis. Prosiding Seminar Nasional Teknik Sipil (Annual Civil Engineering Seminar 2015). Pekanbaru.
Profil Kabupaten Kampar. 2017. Geografis. http://kamparkab.go.id/page/geografis

Raharjo, P. D., A. M. Nur, dan E. Hidayat. 2011. Aplikasi system informasi geografis dalam mengidentifikasi kerawanan bencana alam di kawasan cagar alam geologi Karangsambung. Buletin Geologi Tata Lingkungan (Bulletin of Environmental Geology).21(1): 23 - 33.

Rahmat, B. 2016. Banjir Kampar telan dua korban jiwa. http:pekanbaru.tribunnews.com/2016/0 2/11/banjir-kampar-telan-dua-korbanjiwa. 27 Januari 2017, Pukul 17.43 WIB.

Sukiyah, E. 2004. Aplikasi Sistem Informasi Geografis dalam Penetapan Kawasan Rawan Banjir di Kabupaten Bandung Bagian Selatan. Bulletin of Scientific Contribution. 2 (1) : 26-37.

Sukojo, B.M. 2005. Penyiapan Sumber Manusia Untuk Menunjang Pembangunan Informasi Spasial di Institut Teknologi Sepuluh November (Its) Surabaya, Pertemuan Ilmiah Tahunan MAPIN XIV. Surabaya.

Prahasta, E. 2001. Konsep-konsep dasar sistem informasi geografis. Bandung: Informatika. Profil Kabupaten Kampar. 2017. Geografis. http://kamparkab.go.id/page/geografis 